\title{
Quase impublicável: obras divergentes, relevantes e, sobretudo, simpáticas à pichação em São Paulo
}

Marcos Zibordi

Doutor em Ciências da Comunicação e professor da graduação e do mestrado profissional em Jornalismo do FIAM FAAM - Centro Universitário (SP).

E-mail: mzibordi@hotmail.com

Resumo: A retomada do debate sobre grafites e pichações na capital paulista em 2017 abre a oportunidade de resenhar obras fundamentais da bibliografia pertinente segundo as quais o ato de pichar não é mero vandalismo, pois reverbera, por exemplo, procedimentos de construção da mensagem poética ao modo dos concretistas paulistanos e guarda íntima relação com a arquitetura da metrópole, como as dimensões similares das letras e a altura dos andares dos prédios.

Palavras-chave: grafite; pichação; poesia; São Paulo.
Abstract: The resumption debates about graffiti in the capital of São Paulo in 2017 opens the opportunity to review fundamental works from the pertinent bibliography according to which the act of graffiting is not mere vandalism, for it reverberates, for example, constrution procedures of Concretist's poetic message and is closely related to the architecture of the metropolis, as seen in the similar dimensions of the letters and the height of the buildings' floors.

Keywords: graffiti; pichação; poetry; São Paulo.

Imaginando que o atual prefeito de São Paulo, João Agripino da Costa Doria Júnior, fosse buscar não como político, mas como um gestor, subsídios científicos para embasar sua caça aos pichadores, ficaria decepcionado com a forma respeitosa com que são tratadas as pichações paulistanas, internacionalmente reconhecidas por sua especificidade e valor estético.

Nesta resenha, trataremos de referências sobre pichações publicadas em livro (sim, elas existem), não sem antes nos contrapormos claramente aos fomentadores da pretensa cisão entre grafites e pichações (Gitahy, Casseano, Domenich, Rocha, Malland, Fideles, entre muitos outros). 
1. MORIN, Edgar. Ciência com consciência. Tradução de Maria D. Alexandre e Maria Alice Sampaio Dória. Rio de Janeiro: Bertrand Brasil, 2005 , p. 21

2. DESCARTES, René. Discurso do método. Tradução de Maria Ermantina Galvão. São Paulo: Martins Fontes, 2001, p. 23.

3. MORIN, Edgar. A cabeça bem-feita: repensar a reforma, reformar o pensamento. Rio de Janeiro: Bertrand Brasil, 2010, p. 18.

4. ZIBORDI, Marcos. O rap como religião de salvação. Comunicação \& Inovação, São Caetano do Sul, v. 14, n. 27, (83-88) jul./dez. 2013.

5. GITAHY, Celso. O que é graffiti. São Paulo: Brasiliense, 1999, p. 13.
Falando com Edgar Morin, do ponto de vista complexo, essa tendência teórica maniqueísta nos faz pensar que "se impõe a necessidade do autoconhecimento do conhecimento científico, que deve fazer parte de toda política da ciência, como da disciplina mental do cientista."

O que se combate é, precisamente, a segunda proposta metodológica cartesiana, anunciada há 380 anos em $O$ discurso do método, segundo a qual o pesquisador deveria "dividir cada uma das dificuldades que examinasse em tantas parcelas quanto fosse possível e necessário para melhor resolvê-las."

Cartesianamente, a obsessiva diferenciação entre grafites e pichações é fruto do "paradigma da simplificação" que opera destruindo "os conjuntos e as totalidades" e isolando "todos os objetos daquilo que os envolve".

Do ponto de vista metodológico, revelador do cientista mais do que as opções teóricas, reproduzir a aparentemente fácil distinção entre as incontáveis imagens públicas paulistanas decorre, antes de tudo, da pouca exploração do campo, onde se constata convivência, mais que distinção entre os estilos, sobretudo na capital paulista.

A perspectiva integradora que identifica como grafite as produções figurativas, tipológicas e demais estilos, inclusive aqueles ontem ou hoje chamados de pichação, tem a ver com a trajetória da cultura hip hop. Em sua expansão mundial, mesmo mantendo forte tendência dogmática, como uma religião de salvação ${ }^{4}$, inevitavelmente mudaram os entendimentos quanto aos sentidos representados pelas palavras originalmente norte-americanas com as quais cada parte do mundo identifica os quatro "elementos" da cultura hip hop: a música chamada rap; o trabalho do DJ; a dança, sobretudo o break em São Paulo; e o grafite (com a inclusão, no caso paulistano, de um quinto elemento, o "conhecimento").

E é na capital paulista que a produção visual padece das maiores incompreensões, a começar pela implicância com a especificidade da grafia grafite, como as defesas preciosistas do uso do termo grafitti, plural de grafitto em italiano ${ }^{5}$.

No histórico documentário Style Wars (1983), sobre grafite em Nova York, fica evidente, desde as primeiras cenas, que a maioria dos jovens pintava letras; não por acaso eram os writers, escritores, autores de figuras e tipologias em inscrições coloridas ou não, algumas iguais ao que chamamos atualmente de pichação em São Paulo. O que faziam era chamado de grafite, mas como a História dá voltas, na transição entre as décadas de 1970 e 1980 grafitar em Nova York era tão malvisto quanto pichar na capital paulista hoje em dia, com a coincidência adicional dos prefeitos em guerra contra os infratores visuais, Doria e Ed Koch, seu ancestral político.

Esse mesmo prefeito nova-iorquino aparece no episódio final da primeira temporada da série The Get Down, da Netflix (2016), na qual também são exibidos incontáveis estilos de grafite, inclusive desenhos de letras. Toda a produção é encarada como grafiteira, ramificada em estilos tipológicos, figurativos ou mistos, assim como no documentário mencionado anteriormente. 
Em referências estrangeiras, geralmente não encontramos a distinção moralista entre grafites e pichações, como no entusiasmado ensaio de Baudrillard, no qual a cidade não é mais polo industrial e operário, mas palco de semioses, um "polígono dos signos" para violentas insurreições visuais ${ }^{6}$.

A diferenciação entre os estilos é um problema nacional que ressoou de São Paulo para o Brasil e, assim como a estética das letras crípticas é criação da capital paulista, o debate diferenciador também foi gestado na cidade. Autores de diversas partes do mundo (Inglaterra, França, Estados Unidos, Colômbia e alguns poucos do Brasil, arrolados no próximo tópico) exaltam a vertente pichação como parte integrante da manifestação maior, o grafite, quando não chamam de grafite aquilo que vemos como pichação.

Antes de tentar reconstituir uma resumida linha do tempo bibliográfica, é preciso marcar sem rodeios, como pesquisador e como cidadão, o seguinte: promover a diferença entre grafites e pichações em termos oficiais-midiáticos fomenta a crescente cizânia social brasileira, esse ar de enfrentamento ainda mais patente quando a moral entra em jogo — o grosso da argumentação contra as pichações e a favor dos grafites é escancaradamente moralista, em diferenciações entre o que seria feio e bonito, autorizado ou não, colorido ou não, controlável ou não, cravado no alto incompreensível dos prédios por estetas suicidas na madrugada ou no nível da calçada, acessível ao deleite dos pobres mortais, durante o dia.

\section{O QUE DIZEM AS FONTES}

Facilmente encontrável na internet a preço acessível, o livro Poesia do acaso, de Cristina Fonseca, tem relevância história na bibliografia nacional pelo pioneirismo. Publicado em 1981, instigante edição de texto e imagens, é obra de quem percebeu, logo de cara, a importância da produção visual nas ruas de São Paulo.

Naquele momento, ainda sem o impulso da cultura hip hop, as inscrições nos muros da capital paulista eram simplesmente chamadas de grafites - apesar de que, folheando o livro hoje em dia, os detratores imediatamente acusariam de pichações as imagens publicadas nesta obra fundamental, ainda mais porque Décio Pignatari usa o termo pichação ao apontar as ligações processuais com a paulistaníssima poesia concreta:

E esta é a ligação entre a poesia concreta e o spray: uma consciência do instrumento a ser usado. O spray tem mais consciência física da escritura, não uma simples ideia conceitual, por isso a pichação vira figura icônica. O pichador sabe que tem de estruturar de maneira que leve em conta alguns parâmetros e limitações, para que a escritura funcione. Ele tem que prestar atenção na textura e rugosidade da parede, no tamanho das letras, na cor do spray. Para ele não interessa qualquer tipo de escritura. A qualidade é importante ${ }^{7}$.

Entre as confluências dos processos constitutivos associados mencionamos também, como é peculiar à poesia concreta e à pichação, a imposição do
6. BAUDRILLARD, Jean Kool Killer ou a Insurreição pelos signos. In: A troca simbólica e a morte. São Paulo: Loyola, 1996, p. 106.

7. FONSECA, Cristina. Poesia do acaso. São Paulo: T. A. Queiroz Editor, 1981, p. 38. 
desvendamento da escrita em vários níveis, desde os aspectos semânticos e sintáticos, que estaríamos presumivelmente mais preparados para decifrar, passando pelo ritmo, sonoridade, conteúdo filosófico, social e psicológico, para ficarmos em três óbvios, até as semioses visuais desencadeadas por forma, tamanho, cor, adequação ao espaço, seja ele o papel, os muros, fachadas, orelhões, postes, colunas e, inclusive, o papel, entre outros suportes (Aguilar, Campos, e Pignatari).

Então há um vácuo bibliográfico nas décadas de 1980 e 1990, enquanto a cultura hip hop cresceu e apareceu na capital paulista até virar referência mundial. As imagens ganharam visibilidade e a maioria das pesquisas e publicações sobre elas são posteriores, inegavelmente afetadas pela onipresença dos grafites e pichações, como no livro de fotografias A cidade ilustrada, que, apesar do tom oficialesco, não incorre na tentação distintiva - mesmo sendo o registro de grafiteiros em projeto patrocinado pelo Bank Boston, Prefeitura de São Paulo, Cidade Escola Aprendiz e Suvinil, em 2003.

Comentando o trabalho de artistas como Zezão, conhecido pelas imagens realizadas em esgotos e outros subterrâneos, a obra afirma, em passagem agregadora, que "para manter o elemento underground, alguns deles levam seus graffitis e pichações a lugares que continuam proibidos: o alto dos prédios, postes, orelhões, trens e ônibus"8. Apesar da visão conjuntural, esse belíssimo álbum de fotos celebra o grafite, não a pichação paulistana, que nem teria sentido aparecer numa obra institucional, apesar da solitária foto de um portão totalmente pichado na página 77.

O tom celebrativo e até deslumbrado em relação às pichações aparece em obras de estrangeiros que vieram a São Paulo e foram às ruas, onde, acachapados, produziram registros abrangentes. Nenhum interpreta as pichações como excrescência disforme da capital, a exemplo de Graffiti Brasil, no qual um capítulo é dedicado à pichação e se fala em "grapixo", expressão integradora relativa a produções que misturam grafite e pichação ${ }^{9}$.

No ano seguinte, 2006, vem a público a primeira obra nacional - e até hoje uma das únicas - que assume desde o título a importância estética das inscrições em muros e fachadas. Em edição bilíngue, tem o nome cheio de sonoridade e ironia: Ttsss... a grande arte da pichação em São Paulo, Brasil (2006). É um precioso documento disponível gratuitamente na internet, catálogo de estilos e tendências reunido durante 10 anos por Boleta, que integrou o VÍCIO, um dos mais atuantes e antigos grupos de pichação em São Paulo. Para quem não decifra letras pichadas, o glossário visual no final do volume reproduz cada letra do alfabeto em diversos estilos, ou grafias,

8. SCAVONE, Marcio. A cidade ilustrada. São Paulo: Alice Publishing Editorial, 2004, p. 14

9. ART, Lost; NEELON, Caleb: MANCO, Tristan. Graffiti Brasil. Reino Unido: Thames \& Hudson, 2005, p. 126. um instigante guia para iniciantes.

Para o pesquisador francês François Chastanet, as pichações se relacionam a processos arquitetônicos na constituição de suas respetivas e aproximáveis linguagens. Os resultados da pesquisa em São Paulo saem em livro em 2007, quando Chastanet publica Pixação: São Paulo Signature. Os desenhos esquemáticos da obra impressionam pela clareza ao retratarem semelhanças 
processuais, como a altura das letras em relação ao espaço entre os andares dos prédios, que são molduras para a pichação. Assim, como também no caso das relações com a poesia concreta, novamente se constata a valorização de processos de linguagem caracteristicamente paulistanos.

Mas nenhum desses livros - na verdade, álbuns coloridos em grande formato, impressos em papel nobre — tem a força de $O$ mundo do grafite: arte urbana dos cinco continentes, do fotógrafo alemão Nicholas Ganz, publicado pela primeira vez no Brasil em 2008. Propagandeada como a mais importante obra sobre o assunto, é um catatau de quase 400 páginas com 2 mil imagens de mais de 180 artistas.

O autor viajou o mundo inteiro e afirma que Rio de Janeiro e São Paulo, centros da produção nacional, teriam exercido "a influência mais significativa sobre os estilos mundiais de grafite nos últimos anos"10. Ele também não distingue grafites e pichações e comenta o "grande número de artistas tipográficos elogiados internacionalmente”, destacando estilos genuinamente paulistanos, como a pichação:

O Brasil também é famoso por sua "pixação", um estilo alongado e críptico de escritura que se originou em São Paulo. Seus praticantes - conhecidos como "pixadores" - colocam suas vidas em perigo para alcançar o topo dos edifícios, e não deixam passar em branco nenhuma fachada ${ }^{11}$.

Dois anos depois temos outra obra nacional que, a exemplo das citadas, pode contribuir para elevar o nível do debate. Gustavo Lassala, num esforço classificatório e dignificador, evidencia a importância das pichações para as artes visuais ao lançar, em 2010, o livro Pichação não é pixação: uma introdução à análise de expressões gráficas urbanas. Para ele, "fenômenos legítimos de manifestação social urbana" podem servir de "inspiração para reflexões visuais que podem e devem auxiliar na construção de novas formas de interpretações gráficas da condição em que vivemos"12.

Entre as pesquisas recentes publicadas em livro, o colombiano Armando Silva (2014) adota perspectiva integradora no conjunto da obra, apesar da mal informada distinção entre grafites e pichações, talvez desculpável porque citada de passagem na página 47. Para ele, "balões coloridos, tags ou assinaturas, estênceis, stikers ou selos, e cartazes são novas armas grafiteiras para assaltar os espaços urbanos" ${ }^{\prime 13}$. Assim, mais uma vez, grafite é um conjunto de manifestações visuais de valor estético e político e para o autor a pichação paulistana é derivação de "esplendor fantasmal"14.

Entre as pesquisas que não foram publicadas em livros, o posicionamento teórico integrador entre grafites e pichações é minoritário. Mas existem aqueles que enxergam as afinidades ou "um ponto fundamental da reflexão", que seria a "comunhão subterrânea que possuem, tanto na história das práticas, como nas interdependências processuais para interferirem na cidade"15.

Para outro estudioso,
10. GANZ, Nicholas. 0 mundo do grafite: arte urbana dos cinco continentes. São Paulo: Livraria Martins Fontes, 2010, p. 19.

11. Idem.

12. LASSALA, Gustavo. Pichação não é pixação: uma introdução à análise de expressões gráficas urbanas. São Paulo: Altamira Editorial, 2010, p. 93.

13. SILVA, Armando. Atmosferas urbanas: grafite, arte pública, nichos estéticos. São Paulo: Edições Sesc São Paulo, 2014, p. 143.

14. Ibidem, p. 93.

15. FRANCO, Sérgio Miguel. Iconografias da metrópole: grafiteiros e pichadores representando o contemporâneo. Dissertação de mestrado em Projeto, Espaço e Cultura. Faculdade de Arquitetura, Universidade de São Paulo, São Paulo, 2009, p. 20. 
comunicação \& educação • Ano XXII • número 1 • jan/jun 2017

Os grafiteiros, em sua maioria, consideram a pixação como uma das senão a mais autêntica, formas de graffiti, denominando as letras dos pixadores como Tag reto. Inclusive em outros países o graffiti engloba ambas as formas de manifestação. Não obstante, o traçado das letras dos pixadores no Brasil adquiriu um estilo único, fato que desperta a atenção e a admiração por parte dos grafiteiros de outros países, conferindo uma certa especificidade ao cenário brasileiro ${ }^{16}$.

Pelo poder de síntese, se tivéssemos iniciado com essa citação, provavelmente toda esta resenha poderia ter sido evitada. Mas, se chegamos até aqui, vamos aos três parágrafos conclusivos, a narrativa do pé de manga do vizinho e sua relação com a pichação.

\section{CORTA PARA O INTERIOR PAULISTA}

O anedotário infantil é inesgotável em ensinamentos em qualquer lugar, mas no interior de São Paulo, de onde veio Geraldo Alckmin, padrinho político do prefeito paulistano, os terrenos das casas permitem plantar grandes árvores frutíferas. As crianças tendem, ou tendiam, pelo menos quando este autor viveu a infância na década de 1980, a furtar mangas da árvore do vizinho, mesmo que em seu quintal o pé estivesse a perder de frutas.

Explicação dos mais velhos: a manga do vizinho é sempre mais gostosa, ou a subversão atrai mais do que uma fruta doce e amarelinha, mera desculpa para pular o muro - novamente o muro, pulado no interior enquanto, na capital, ganhava registros de spray. Nos dois casos, a necessidade fundamental a saciar não era a fome, mas o prazer de infringir a ordem.

Daí que a campanha vociferante contra a pichação padece do precioso ensinamento interiorano, por demais frutífero: no final das contas, ao invés de reprimir, a repressão promove a pichação, porque a manga furtada ao vizinho é sempre mais gostosa, ou, como belamente sintetiza Armando Silva, “o imaginário rebelde procede contra a repressão, mas a própria repressão é sua profunda verdade"17.

16. FERREIRA, Lucas Tavares. O traçado das redes: etnografia dos grafiteiros e a sociabilidade na metrópole. Dissertação de mestrado em Ciências Sociais. Centro de Educação e Ciências Humanas, Universidade Federal de São Carlos, São Carlos, 2006, p. 37.

17. Silva, op. cit., p. 83.

\section{REFERÊNCIAS BIBLIOGRÁFICAS}

AGUILAR, Gonzalo. Poesia concreta brasileira: as vanguardas na encruzilhada modernista. São Paulo: Edusp, 2005.

ART, Lost; NEELON, Caleb; MANCO, Tristan. Graffiti Brasil. Reino Unido: Thames \& Hudson, 2005.

BOLETA. Ttsss... A grande arte da pixação em São Paulo. São Paulo: Editora do Bispo, 2006.

CAMPOS, Augusto, CAMPOS, Haroldo, PIGNATARI, Décio. Teoria da poesia concreta. Textos críticos e manifestos 1950-1960. São Paulo: Livraria Duas Cidades, 1975. 
CHAStAnet, François. Pixação: São Paulo signature. Toulouse: XGpress, 2007.

BAUDRILLARD, Jean. Kool Killer ou a Insurreição pelos signos. In: A troca simbólica e a morte. São Paulo: Loyola, 1996.

CASSEANO, Patrícia; DOMENICH, Mirella; ROCHA, Janaína. Hip Hop, a periferia grita. São Paulo: Editora Fundação Perseu Abramo, 2001.

DESCARTES, René. Discurso do método. Tradução de Maria Ermantina Galvão. São Paulo: Martins Fontes, 2001.

FERREIRA, Lucas Tavares. O traçado das redes: etnografia dos grafiteiros e a sociabilidade na metrópole. Dissertação de mestrado em Ciências Sociais. Centro de Educação e Ciências Humanas, Universidade Federal de São Carlos, São Carlos, 2006.

FIDELES, Nina (Org.). O movimento hip hop no Brasil. São Paulo: Editora Caros Amigos, 2014.

FONSECA, Cristina. Poesia do acaso. São Paulo: T. A. Queiroz Editor, 1981.

FRANCO, Sérgio Miguel. Iconografias da metrópole: grafiteiros e pichadores representando o contemporâneo. Dissertação de mestrado em Projeto, Espaço e Cultura. Faculdade de Arquitetura, Universidade de São Paulo. São Paulo, 2009.

GANZ, Nicholas. O mundo do grafite: arte urbana dos cinco continentes. Nova edição revista e ampliada. São Paulo: Livraria Martins Fontes, 2010.

GITAHY, Celso. O que é graffiti. São Paulo: Brasiliense, 1999.

GUIRGIS, Adly, LUHRMANN, Baz. The Get Down. EUA, Netflix, 2016.

LASSALA, Gustavo. Pichação não é pixação: uma introdução à análise de expressões gráficas urbanas. São Paulo: Altamira Editorial, 2010.

MALLAND, Julien Seth. Tropical spray. São Paulo: Martins Fontes, 2012.

MORIN, Edgar. Ciência com consciência. Tradução de Maria D. Alexandre e Maria Alice Sampaio Dória. Ed. revista e modificada pelo autor. Rio de Janeiro: Bertrand Brasil, 2005.

A cabeça bem-feita: repensar a reforma, reformar o pensamento. Rio de Janeiro: Bertrand Brasil, 2010.

PIGNATARI, Décio. O que é comunicação poética. Cotia: Ateliê Editorial, 2005.

SCAVONE, Marcio. A cidade ilustrada. São Paulo: Alice Publishing Editorial, 2004. 
SILVA, Armando. Atmosferas urbanas: grafite, arte pública, nichos estéticos. São Paulo: Edições Sesc São Paulo, 2014.

SILVER, Tony. Style Wars. EUA, Public Art Films, 1984.

ZIBORDI, Marcos. "O rap como religião de salvação". Comunicação \& Inovação, São Caetano do Sul, v. 14, n. 27, (83-88) jul./dez. 2013. 